\title{
DIAGNOSTIC ACCURACY OF PLATELET COUNT FOR PREDICTION OF ESOPHAGEAL VARICES IN PATIENTS PRESENTING WITH CHRONIC LIVER DISEASE.
}

\footnotetext{
1. BDS, M.Phil

Assistant Professor

Department of Science of Dental Materials

Bacha Khan Dental College,

Mardan

2. BDS, FCPS

Associate Professor

Department of Prosthodontics

Peshawar Dental College, Peshawar.

3. BDS, M.Phil

Assistant Professor

Department of Pathology

Khyber Medical College, Peshawar.

4. BDS, M.Phil

Lecture

Bacha Khan Dental College,

Mardan.
}

Correspondence Address:

Dr. Muhammad Raza

Gucha Captan Lal Khan,

Bazar Topan Wala, Dera Ismail, Khan

hmraza77@yahoo.com

Article received on:

27/10/2018

Accepted for publication:

$15 / 07 / 2019$

\begin{abstract}
Siraj ud Din Barech ${ }^{1}$, Tahir Ullah Khan², Muhammad Niaz Khan ${ }^{3}$
ABSTRACT: Thrombocytopenia increases the risk of bleeding in CLD patients. The determination of the presence of Esophageal Varices (EV) by endoscopy is an invasive procedure. As a noninvasive tool, low platelet count (PC) can be helpful in prediction of variceal bleed in CLD patients with esophageal varices. Objectives: To assess the diagnostic accuracy of thrombocytopenia in predicting the presence of esophageal varices in patients with chronic liver disease. Study Design: Descriptive Cross sectional study. Setting: Medicine Unit I, Sheikh Zayed Hospital, Lahore. Period: 6 months from 1-07-2015 to 31-12-2015. Material and Methods: About 150 cases were included in our study through Non-Probability, Consecutive sampling method after obtaining written Informed consent. Blood sample was obtained from each patient and were immediately sent to the laboratory for assessment of platelet count. Reports were assessed. Those with low platelet count were referred to endoscopy room for confirmation of esophageal varices. Reports of endoscopy were compared with platelet count. Data was entered and analyzed through SPSS version 23. Results: Mean age of patients was $49.64 \pm 11.54$ years. There were $97(64.7 \%)$ male and $53(35.3 \%)$ female patients. Mean duration of chronic liver disease of patients was $3.51 \pm 1.39$. Mean platelet count of patients was $172.3 \pm 81.20$. Sensitivity and Specificity of Thrombocytopenia for prediction of esophageal varices in patients presenting with chronic liver disease was $92.63 \%$ and $89.09 \%$. While PPV, NPV and Diagnostic accuracy of Thrombocytopenia for prediction of esophageal varices was 93.62\%, $87.5 \%$ and $91.33 \%$ respectively. Conclusion: It has been concluded from the present study that PC has high accuracy for detection of EVs and can be helpful in prediction of EVs in CLD patients.
\end{abstract}

Key words: Chronic Liver Disease, Diagnostic Accuracy, Endoscopy, Esophageal Varices, Platelet Count, Variceal Bleed.

Article Citation: Barech S, Khan T, Khan MN. Diagnostic accuracy of Platelet Count for prediction of Esophageal varices in patients presenting with Chronic Liver disease. Professional Med J 2020; 27(1):16-22.

DOI: 10.29309/TPMJ/2020.27.1.1368

\section{INTRODUCTION}

Thrombocytopenia defined as platelet count $<150,000$ /microliter is present in about $76 \%$ of patients with chronic liver disease and responsible for significant number of complications. ${ }^{1,2}$ Thrombocytopenia increases the risk of bleeding during and after invasive procedures and may result in the cancellation or postponement of elective procedures. ${ }^{2,3}$ Development of portal hypertension with consequent esophageal varices $(E V)$ is an alarming sign in cirrhotic patients because of the high mortality due to upper Gl bleed. Approximately $60-80 \%$ patients with newly diagnosed cirrhosis have evidence of esophageal varices. The risk of bleeding from esophageal varices depends upon the size of the varices (5\% for small sized esophageal varices and $15 \%$ for large sized esophageal varices). ${ }^{4,5}$

According to observations of Schepis and his colleagues, about 44\% CLD patients with platelet count of $<100,000$ had evidence of EV on upper Gl endoscopy. ${ }^{6}$ Therefore, documenting the presence of EV via upper GI endoscopy in newly diagnosed cirrhotic patients is mandatory. ${ }^{5}$ To date, endoscopy is the gold standard for screening of EVs. ${ }^{7-9}$ In a study, the sensitivity and specificity of decreased PC were $80 \%$ and 90 respectively \% with PPV and NPV of $98.8 \%$ and $29 \%$ respectively. ${ }^{10}$ 
Rationale of this study is to find the diagnostic accuracy of decreased platelet count for prediction of esophageal varices in patients with chronic liver disease taking endoscopy as gold standard. Literature has reported that PC can be helpful in prediction of EVs in CLD patients as it can be a non-invasive procedure for patients and can help in early prediction of EVs in such critical cases. However, in literature there is little ambiguity observed that showed the diagnostic accuracy can be uncertain as some showing it low while others showing $>80 \%$. So we want conduct this study to find whether PC can be helpful in future for early prediction of EVs in CLD patients.

\section{MATERIALS \& METHODS}

The present study was conducted at Medicine Unit I , Sheikh Zayed Hospital, Lahore extending over a duration of 6 months from 1-7-2015 to 3112- 2015. Total numbers of subjects in our study were 150, applying a 95\% confidence interval. Expected percentage of esophageal varices was taken as $44 \%{ }^{6}$ with sensitivity of decreased PC as $80 \%$ with $9 \%$ margin of error and specificity of decreased platelet count as $90 \%{ }^{11}$ with $6 \%$ margin of error respectively. Endoscopy was taken as gold standard for diagnosing esophageal varices in CLD patients. Non-Probability, Consecutive sampling method was applied. Patients included in our study were of age 30-70years of either gender presenting with documented CLD >1 year. Patients excluded from our study were those taking beta-blockers, receiving sclerotherapy or history of band ligation for previous varices or bleeding and patients with malignancy or metastasis. After taking official letter of approval from ethical board of SZH, 150 patients satisfying the inclusion criteria were enrolled in the research work from medical OPD. After obtaining Informed consent from the study participants, demographic details were noted. Then blood sample was obtained from each patient with the help of a staff nurse by using $5 \mathrm{cc}$ BD syringe which was stored in container. The samples were immediately sent to the laboratory for assessment of platelet count by using CBC method. Reports were assessed. Those with low platelet count were labeled as positive for esophageal varices and referred to endoscopy room for confirmation of esophageal varices. All endoscopies were done by a senior gastroenterologist. Reports of endoscopy were compared with reports of platelet count. All this information was recorded in the Performa. SPSS version 23 was applied for data entry and analysis. Quantitative variables were calculated as mean \pm SD while qualitative variables were assessed as Frequency and percentages. Using 2x2 tables, the sensitivity, specificity, positive predictive value, negative predictive value and diagnostic accuracy of platelet count were assessed. In order to overcome the effect modifiers, data was stratified for age, gender, duration of CLD and severity of CLD (Child Pugh class). After data stratification, chi-square test was applied. $P$-value $\leq 0.05$ was taken as significant.

\section{RESULTS}

Mean age of patients was $49.64 \pm 11.54$ years with age range between 30 to 70 years (Table-I). Regarding Gender distribution, about 97(64.7\%) were male and 53(35.3\%) were female (Figure-1). Mean duration of chronic liver disease of patients was $3.51 \pm 1.39$. Minimum and maximum duration of disease was 1 and 6 respectively (Table-II). There were $33(22 \%)$ patients whose Child Pugh class was A, 99 (66\%) patients child Pugh Class was $B$ and $18(12 \%)$ patients Child Pugh Class was $\mathrm{C}$ (Table-III). Mean platelet count of patients was $172.3 \pm 81.20$. Minimum and maximum platelet count was 85 and 350 (Table-IV). Among 94(62.6\%) patients laboratory findings were positive while in remaining $56(37.3 \%)$ patients laboratory findings were negative (Table-V). Among 95(63.3\%) patients endoscopic findings were positive while among remaining $55(36.7 \%)$ patients endoscopic findings were negative (Table-VI). Sensitivity and Specificity of Thrombocytopenia for prediction of esophageal varices in patients presenting with chronic liver disease was $92.63 \%$ and $89.09 \%$. While PPV, NPV and Diagnostic accuracy of Thrombocytopenia for prediction of esophageal varices was $93.62 \%$, $87.5 \%$ and $91.33 \%$ respectively (Table-VII). Diagnostic accuracy of Thrombocytopenia for prediction of esophageal varices in the age group 30-40 years was: Sensitivity: 90.91\%, Specificity: 84.62\%, PPV: $90.91 \%$, NPV: $84.62 \%$ \& Diagnostic 
Accuracy: $88.57 \%$. In the age group $41-50$ years Diagnostic accuracy of Thrombocytopenia was: Sensitivity: $91.3 \%$, Specificity: $80 \%$, PPV: $84 \%$, NPV: $88.89 \%$ \& Diagnostic Accuracy: $86.05 \%$. In the age group 51-60 years Diagnostic accuracy of Thrombocytopenia was: Sensitivity: $92.86 \%$, Specificity: 100\%, PPV: 100\%, NPV: $85.71 \%$ \& Diagnostic Accuracy: 95\%. In the age group 61-70 years Diagnostic accuracy of Thrombocytopenia was: Sensitivity: $95.45 \%$, Specificity: 100\%, PPV: 100\%, NPV: $90.91 \%$ \& Diagnostic Accuracy: 96.88\%. (Table-VIII). Among male patients diagnostic accuracy of Thrombocytopenia was: Sensitivity: $93.55 \%$, Specificity: $85.71 \%$, PPV: 92.06\%, NPV: $88.24 \%$ \& Diagnostic Accuracy: $90.72 \%$. Among female patients diagnostic accuracy of Thrombocytopenia was: Sensitivity: 90.91\%, Specificity: 95\%, PPV: 96.77\%, NPV: 86.36\% \& Diagnostic Accuracy: 92.45\%. (TableIX). Patients whose duration of CLD was 1-2 years among them diagnostic accuracy of Thrombocytopenia was: Sensitivity: $72 \%$, Specificity: 53.85\%, PPV: $75 \%$, NPV: $50 \%$ \& Diagnostic Accuracy: $65.79 \%$. However patients whose duration of CLD disease was 3-4 and 5-6 years among them diagnostic accuracy of Thrombocytopenia was: Sensitivity: 100\%, Specificity: 100\%, PPV: 100\%, NPV: 100\% \& Diagnostic Accuracy: 100\% (Table-X). Patients who had Child Pugh class $A$ among these patients, the diagnostic accuracy was: Sensitivity: 78.26\%, Specificity: 50\%, PPV: $78.26 \%$, NPV: 50\% \& Diagnostic Accuracy: 69.7\%. Diagnostic accuracy of Thrombocytopenia in patients with Child Pugh Class B was: Sensitivity: $96.83 \%$, Specificity: 97.22\%, PPV: 98.39\%, NPV: $94.59 \%$ \& Diagnostic Accuracy: $96.97 \%$. In patients with Child Pugh Class $\mathrm{C}$ diagnostic accuracy was: Sensitivity: 100\%, Specificity: 100\%, PPV: 100\%, NPV: $100 \%$ \& Diagnostic Accuracy: 100\% (Table$\mathrm{XI})$.

\begin{tabular}{|l|c|}
\hline \multicolumn{1}{|c|}{$\mathbf{N}$} & $\mathbf{1 5 0}$ \\
\hline Mean & 49.64 \\
\hline SD & 11.54 \\
\hline Minimum & 30 \\
\hline Maximum & 70 \\
\hline
\end{tabular}

Table-I. Age distribution of patients

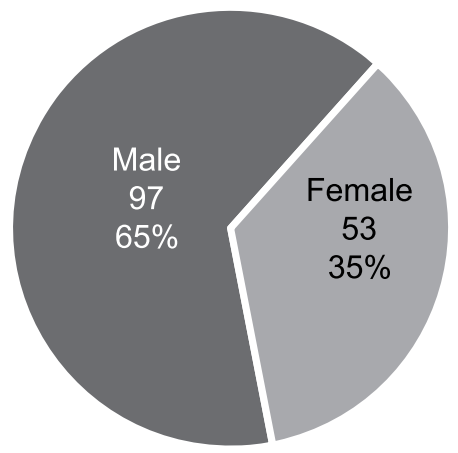

Figure-1. Gender distribution of patients

\begin{tabular}{|l|c|}
\hline \multicolumn{1}{|c|}{$\mathbf{n}$} & $\mathbf{1 5 0}$ \\
\hline Mean & 3.51 \\
\hline SD & 1.39 \\
\hline Minimum & 1 \\
\hline Maximum & 6 \\
\hline
\end{tabular}

Table-II. Descriptive statistics for duration of CLD

\begin{tabular}{|c|c|c|}
\hline & Frequency & Percentage \\
\hline A & 33 & $22 \%$ \\
\hline B & 99 & $66 \%$ \\
\hline Total & 18 & $12 \%$ \\
\hline
\end{tabular}

Table-III. Distribution of patients as per child PUGH class

\begin{tabular}{|l|c|c|}
\hline \multicolumn{1}{|c|}{$\mathbf{n}$} & \multicolumn{2}{c|}{150} \\
\hline Mean & \multicolumn{2}{|c|}{172.13} \\
\hline SD & \multicolumn{2}{|c|}{81.20} \\
\hline Minimum & \multicolumn{2}{|c|}{85} \\
\hline Maximum & \multicolumn{2}{|c|}{350} \\
\hline \multicolumn{2}{|c|}{ Table-IV. Descriptive statistics for platelet count } \\
\hline Laboratory Findings & Frequency & Percentage \\
\hline Positive & 94 & $62.7 \%$ \\
\hline Negative & 56 & $37.3 \%$ \\
\hline Total & 150 & $100 \%$ \\
\hline
\end{tabular}

Table-V. Laboratory findings of patients

\begin{tabular}{|l|c|c|}
\hline Endoscopic Findings & Frequency & Percentage \\
\hline Positive & 95 & $63.3 \%$ \\
\hline Negative & 55 & $36.7 \%$ \\
\hline Total & 150 & $100 \%$ \\
\hline
\end{tabular}

Table-VI. Endoscopic findings of patients 


\begin{tabular}{|c|c|c|c|c|}
\hline \multicolumn{2}{|c|}{} & \multicolumn{2}{|c|}{$\begin{array}{c}\text { Endoscopic } \\
\text { Findings }\end{array}$} & \multirow{2}{*}{ Total } \\
\cline { 3 - 5 } & & Positive & Negative & \\
\hline \multirow{2}{*}{$\begin{array}{c}\text { Thrombo- } \\
\text { cytopenia }\end{array}$} & Positive & 88 & 6 & 94 \\
\hline \multicolumn{2}{|c|}{ Total } & 7 & 49 & 56 \\
\hline \multicolumn{2}{|c|}{ Togative } & 95 & 55 & 150 \\
\hline
\end{tabular}

Sensitivity $=92.63 \%$

Specificity $=89.09 \%$

PPV $=93.62 \%$

NPV $=87.5 \%$

Diagnostic Accuracy $=91.33 \%$

Table-VII. Diagnostic accuracy of platelet count for prediction of esophageal varices

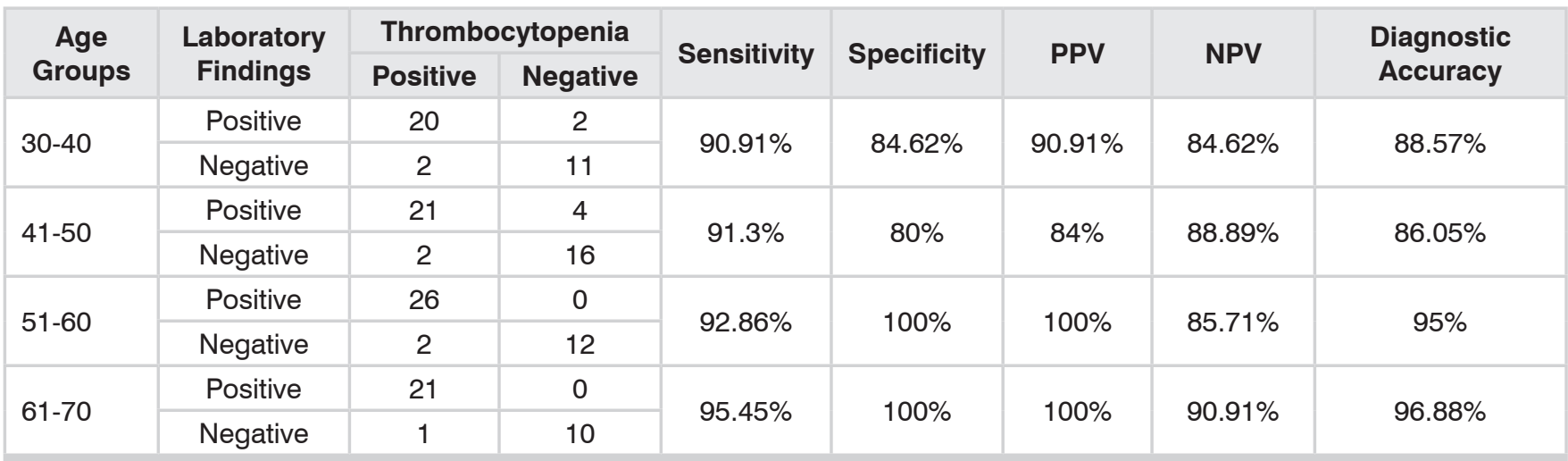

Table-VIII. Diagnostic accuracy of platelet count for prediction of esophageal varices in relation to age of patients

\begin{tabular}{|c|c|c|c|c|c|c|c|c|}
\hline \multirow{2}{*}{ Gender } & \multirow{2}{*}{$\begin{array}{l}\text { Laboratory } \\
\text { Findings }\end{array}$} & \multicolumn{2}{|c|}{ Thrombocytopenia } & \multirow{2}{*}{ Sensitivity } & \multirow{2}{*}{ Specificity } & \multirow{2}{*}{ PPV } & \multirow{2}{*}{ NPV } & \multirow{2}{*}{$\begin{array}{c}\text { Diagnostic } \\
\text { Accuracy }\end{array}$} \\
\hline & & Positive & Negative & & & & & \\
\hline \multirow{2}{*}{ Male } & Positive & 58 & 5 & \multirow{2}{*}{$93.55 \%$} & \multirow{2}{*}{$85.71 \%$} & \multirow{2}{*}{$92.06 \%$} & \multirow{2}{*}{$88.24 \%$} & \multirow{2}{*}{$90.72 \%$} \\
\hline & Negative & 4 & 30 & & & & & \\
\hline \multirow{2}{*}{ Female } & Positive & 30 & 1 & \multirow{2}{*}{$90.91 \%$} & \multirow{2}{*}{$95 \%$} & \multirow{2}{*}{$96.77 \%$} & \multirow{2}{*}{$86.36 \%$} & \multirow{2}{*}{$92.45 \%$} \\
\hline & Negative & 3 & 19 & & & & & \\
\hline
\end{tabular}

Table-IX. Diagnostic accuracy of platelet count for prediction of esophageal varices in relation to gender of patients

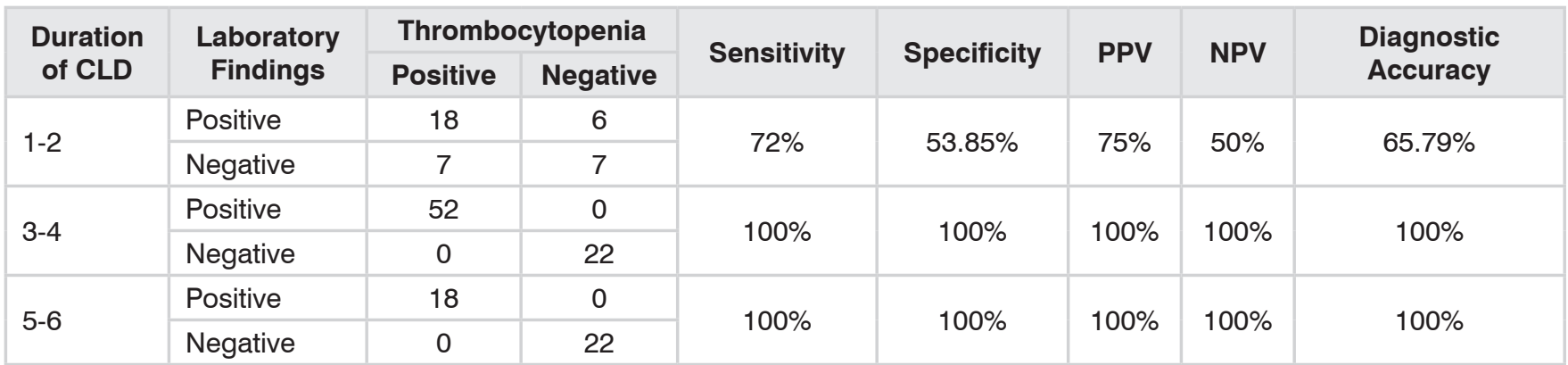

Table-X. Diagnostic accuracy of platelet count for prediction of esophageal varices in relation to duration of CLD

\begin{tabular}{|c|c|c|c|c|c|c|c|c|}
\hline \multirow{2}{*}{$\begin{array}{c}\text { Child Pugh } \\
\text { Class }\end{array}$} & \multirow{2}{*}{$\begin{array}{l}\text { Laboratory } \\
\text { Findings }\end{array}$} & \multicolumn{2}{|c|}{ Thrombocytopenia } & \multirow{2}{*}{ Sensitivity } & \multirow{2}{*}{ Specificity } & \multirow{2}{*}{ PPV } & \multirow{2}{*}{ NPV } & \multirow{2}{*}{$\begin{array}{c}\text { Diagnostic } \\
\text { Accuracy }\end{array}$} \\
\hline & & Positive & Negative & & & & & \\
\hline A & Positive & 18 & 5 & $78.26 \%$ & $50 \%$ & $78.26 \%$ & $50 \%$ & $69.7 \%$ \\
\hline \multirow{2}{*}{ B } & Positive & 61 & 1 & \multirow{2}{*}{$96.83 \%$} & \multirow{2}{*}{$97.22 \%$} & \multirow{2}{*}{$98.39 \%$} & \multirow{2}{*}{$94.59 \%$} & \multirow{2}{*}{$96.97 \%$} \\
\hline & Negative & 2 & 35 & & & & & \\
\hline C & Negative & 0 & 9 & $100 \%$ & $100 \%$ & $100 \%$ & $100 \%$ & $100 \%$ \\
\hline
\end{tabular}

Table-XI. Diagnostic accuracy of platelet count for prediction of esophageal varices in relation to child PUGH class 


\section{DISCUSSION}

According to recent recommendations, a consensus has been developed on screening upper Gl endoscopy in all newly diagnosed cirrhotic patients which not only puts a huge workload on endoscopy units but also gives rise to immense problems in terms of patient compliance and tolerability. In order to overcome these problems, non-invasive methods of identifying patients at highest risk for esophageal varices was the need of the day which would greatly limit the investigative work up to the patient benefit. Therefore, a search for noninvasive tests was needed. ${ }^{11}$

Thrombocytopenia (platelet count < 150,000/ $\mu \mathrm{l}$ ) is a common complication in patients of chronic liver disease (CLD). ${ }^{12}$ Thrombocytopenia is reported in as many as $76 \%$ of cirrhotic patients. ${ }^{13}$ In the past 10 years, various clinical and laboratory parameters e.g. ascites, spider naevi, splenic enlargement, Child's pugh scoring, PC , PT, PV diameter, platelet count/ spleen diameter ratio, serum albumin, and serum bilirubin, have been used to assess the presence of esophageal varices in cirrhotic patients. Spleen size is becoming increasingly important because both splenomegaly and EV may be related to high portal pressure; also, splenomegaly may increase platelet sequestration and lead to a low platelet count. ${ }^{14}$

As per results of this study Sensitivity and specificity of thrombocytopenia was $92.63 \%$ and 89.09\%. While PPV, NPV and diagnostic accuracy of thrombocytopenia was $93.62 \%, 87.5 \%$ and 91.33\% respectively. According to observations of Rulprakash Sarangapani, the sensitivity and specificity of thrombocytopenia (platelets < $150,000 / \mathrm{mm})^{3}$ for predicting the presence of esophageal varices is $72.5 \%$ and $75 \%$ respectively with PPV of $63.8 \%$ and NPV of $70.5 \% .{ }^{15}$ Diagnostic accuracy of thrombocytopenia for EV of our study was high as that reported by Arulprakash Sarangapani. Using platelet count and child pugh scoring, Burton et al. proposed two models for presence/size of esophageal varices. The first model was proposed to detect large esophageal varices in cirrhotic patients with platelet count
$<80$ and Child-Pugh score A. The results were as: sensitivity $58 \%$, specificity $79 \%$, Positive predictive value $30 \%$, and Negative predictive value $92 \%$. The second model was proposed to detect esophageal varices of any size in cirrhotic patients having Child class $\mathrm{B} / \mathrm{C}$ and platelet count <90. The results were as: sensitivity $60 \%$, specificity $59 \%$, PPV $80 \%$, and NPV $34 \%$. However, there were pitfalls in these models which led to their failure in reliably predicting esophageal varices. ${ }^{16}$

Burton et al. in his study used different cut point as that of this study for platelet count which might be the reason for low sensitivity and specificity for thrombocytopenia for esophageal varices. Findings of a local study from Pakistan showed that the sensitivity and specificity of decreased PC were $99.2 \%$ and $90.2 \%$ respectively and PPV and NPV were $97.1 \%$ and $97.3 \%$ respectively taking endoscopy as gold standard. These results are consistent with our results. ${ }^{17}$ HeshamEzzEldin Said from Egypt reported the diagnostic accuracy of thrombocytopenia in esophageal varices in cirrhotic patients as $80 \%$ sensitivity, $90 \%$ specificity, 98.8\% PPV and 29\% NPV. ${ }^{18}$ Diagnostic accuracy parameters for thrombocytopenia in study is consistent with the results reported by HeshamEzzEldin except one parameter i.e. NPV which was $29 \%$ reported by HeshamEzzEldin and in this study it was $87.5 \%$. This huge difference in NPV was may be due to difference in sample size or due to patient's presentation, severity and other disease related characteristics. According to observations made by Zein and his colleagues, platelet count of $<150000$ had a sensitivity of $88 \%$ and specificity $76 \%$ for detection of esophageal varices..$^{19}$ Thomopoulosetal. (184 patients) found that platelet count $<118 \times 10^{3}$ was good predictor for presence of varices with sensitivity $95 \%$, and specificity $73 \%{ }^{20}$

As per of this study it can be concluded that thrombocytopenia can be used to stratify risk for occurrence of esophageal varices in cirrhotic patients and may be of great value to the gastroenterologists working in far-flung areas lacking health facilities and endoscopy set-ups. 


\section{CONCLUSION}

It has been concluded through results of this study that PC has high accuracy for detection of EVs and can be used as a noninvasive tool in prediction of EVs in CLD patients.

\section{Copyright@ 12 March, 2019.}

\section{REFERENCES}

1. Afdhal N, McHutchison J, Brown R, Jacobson I, Manns $\mathrm{M}$, Poordad F, et al. Thrombocytopenia associated with chronic liver disease. J Hepatol 2008 Jun; 48(6):1000-7.

2. Afdhal NH, Giannini EG, Tayyab G, Mohsin A, Lee J-W, Andriulli $A$, et al. Eltrombopag before procedures in patients with cirrhosis and thrombocytopenia. New England Journal of Medicine 2012; 367(8):716-24.

3. Hayashi H, Beppu T, Shirabe K, Maehara Y, Baba H. Management of thrombocytopenia due to liver cirrhosis: A review. World journal of gastroenterology: WJG 2014; 20(10):2595.

4. Garcia-Tsao G, Bosch J. Management of varices and variceal hemorrhage in cirrhosis. New England Journal of Medicine 2010; 362(9):823-32.

5. Mahassadi AK, Bathaix FY, Assi C, Bangoura AD, AllahKouadio E, Kissi HY, et al. Usefulness of noninvasive predictors of oesophageal varices in black african cirrhotic patients in Côte d'Ivoire (West Africa). Gastroenterology research and practice 2012; 2012.

6. Schepis F, Cammà C, Niceforo D, Magnano A, Pallio $S$, Cinquegrani $M$, et al. Which patients with cirrhosis should undergo endoscopic screening for esophageal varices detection? Hepatology 2001; 33(2):333-8.

7. Thabut D, Moreau R, Lebrec D. Screening for esophageal varices: Endoscopy, other tools, or endoscopy and other tools? Hepatology 2008; 47(5):1434-6.

8. de Franchis R. Revising consensus in portal hypertension: Report of the Baveno V consensus workshop on methodology of diagnosis and therapy in portal hypertension. Journal of hepatology 2010; 53(4):762-8.

9. Bosch J, Berzigotti A, Seijo S, Reverter E. Assessing portal hypertension in liver diseases: Goldstandard technique to assess the presence of gastroesophageal varices: Endoscopy. Expert Rev Gastroenterol Hepatol 2013;7(3):1-15.
10. Said HEE, Elsayed EY, Ameen A, Elal HA. Cytopenia as a predictor of oesophageal varices in patients with liver cirrhosis. Rep Opin 2010; 2(7):35-41.

11. Rye K, Scott R, Mortimore G, Lawson A, Austin A, Freeman $J$. Towards noninvasive detection of oesophageal varices. International journal of hepatology 2012; 2012.

12. Zwicker JI DR. Hematologic disorders and the liver.. In: Schiff ER SM, Maddrey WC, editor. Schiff's diseases of the liver. Philadelphia: Lippincott Williams \& Wilkins; 2007. p. 349-63.

13. Giannini E. Review article: thrombocytopenia in chronic liver disease and pharmacologic treatment options. Alimentary pharmacology \& therapeutics 2006; 23(8):1055-65.

14. EINaggar AA, Gomaa MS, Fawzy MM. Nonendoscopic predictors of large esophageal varices. The Egyptian Journal of Internal Medicine 2012; 24(3):97.

15. Sarangapani $A^{1}$, Shanmugam $C$, Kalyanasundaram $M$, Rangachari $B$, Thangavelu $P$, Subbarayan JK. Noninvasive prediction of large esophageal varices in chronic liver disease patients. Saudi J Gastroenterol. 2010 Jan-Mar; 16(1):38-42. doi: 10.4103/1319-3767.58767.

16. Burton Jr JR, Liangpunsakul S, Lapidus J, Giannini E, Chalasani N, Zaman A. Validation of a multivariate model predicting presence and size of varices. Journal of clinical gastroenterology 2007; 41(6):609-15.

17.Imran M, Iqbal J, Raffad. Detection of esophageal varices in liver cirrhosis using platelet count as a non-invasive parameters. Esculapio 2011; 7(1):2-5.

18. Said $\mathrm{H}$, Elsayed $\mathrm{E}$, Ameen $\mathrm{A}$, AbdEla $\mathrm{H}$. Cytopenia as a predictor of oesophageal varices in patients with liver cirrhosis. Rep Opin 2010; 2:35-41. 11.

19. Zein CO, Lindor KD, Angulo P. Prevalence and predictors of esophageal varices in patients with primary sclerosing cholangitis. Hepatology 2004; 39(1):204-1075.

20. Thomopoulos K, Labropoulou-Karatza C, Mimidis K, Katsakoulis E, Iconomou G, Nikolopoulou V. Noninvasive predictors of the presence of large oesophageal varices in patients with cirrhosis. Digestive and liver disease 2003; 35(7):473-8. 


\begin{tabular}{|c|c|c|c|}
\hline \multicolumn{3}{|c}{ AUTHORSHIP AND CONTRIBUTION DECLARATION } \\
\hline Sr. \# & Author(s) Full Name & \multicolumn{1}{|c|}{ Contribution to the paper } & Author(s) Signature \\
\hline 1 & Siraj ud Din Barech & $\begin{array}{l}\text { Hypothesis, designing, Data } \\
\text { collection, Article arrangement } \\
\text { \& Finalization. } \\
\text { Statistical Analysis preparation } \\
\text { of manuscript design, } \\
\text { references style tables and } \\
\text { figures. } \\
\text { Proof reading, Final review. }\end{array}$ \\
\hline 3 & Tahir Ullah Khan & Muhammad Niaz Khan & \\
\hline
\end{tabular}

